ri e virus e caratterizzati da assenza di parete cellulare e da insensibilità agli antibiotici che agiscono su di essa. Negli ultimi anni sempre più discusso è il ruolo dei Mycoplasmi, quali agenti responsabili di Uretriti non gonococciche (UNG) nonché di salpingiti, metriti e cerviciti croniche. Nostro scopo è quello di valutare la loro prevalenza nella nostra popolazione.

Materiali e metodi. Il campione è costituito da 3758 donne (di età compresa tra i 15 e i 60 anni), afferenti al nostro laboratorio nel periodo gennaio 2003- maggio 2005.

$\mathrm{Su}$ tale popolazione è stato effettuato il tampone cervicale con terreno di trasporto di Amies; per la ricerca di Ureaplasma/Mycoplasma è stato utilizzato il kit MYCOPLASMA IST della ditta Biomerieux.

Risultati. Sono così sintetizzabili:

\begin{tabular}{lccc}
\hline & $\begin{array}{c}\text { Numero } \\
\text { campioni }\end{array}$ & $\begin{array}{c}\text { Numero } \\
\text { campioni } \\
\text { positivi }\end{array}$ & $\begin{array}{c}\% \\
\text { positività }\end{array}$ \\
\hline Ureaplasma urealyticum & 3758 & 954 & 25.4 \\
\hline Mycoplasma hominis & 3758 & 120 & 3,2 \\
\hline
\end{tabular}

Conclusioni. I risultati del nostro lavoro confermano quanto gia indicato in letteratura in merito al diverso ruolo patogeno di U. urealyticum e M. hominis. Infatti il primo svolgerebbe ruolo di copatogeno in quanto frequentemente associato ad altri patogeni (nel nostro campione Gardnerella nel 15\% e Candida spp. nel 13\%), mentre M. hominis sarebbe responsabile di metriti e salpingiti croniche, raggruppabili nella Mal. Infiammatoria Pelvica.

\title{
BIBLIOGRAFIA:
}

1. Mardh PA-. Tubal factor infertility, with special regard to chlamydial salpingitis.-Curr Opin Infect Dis. 2004 Feb; 17 (I): 49-52.

\section{STUDIO DI PREVALENZA DELLE INFEZION DA MYCOPLASMI DA T. CERVICALE NEL TERRITORIO DI FASANO-OSTUNI (BR).}

Muolo V., Andriulo B., , Ostuni A.M. , Pannofino A.,Vinci E.

U.O. Patologia Clinica Ostuni-Fasano, AUSL BR/I.

Obiettivo. I Mycoplasmi, appartenenti alla famiglia delle Mycoplasmataceae, genere Mollicutes, sono piccoli microrganismi pleiomorfici, ritenuti una via di transizione tra batte- 